\title{
The discriminatory capability of polarimetric SAR data for land use classification*
}

\author{
Sidnei João Siqueira Sant'Anna \\ Antonio Henrique Correia \\ Corina da Costa. Freitas \\ INPE-DPI \\ Av. dos Astronautas 1758, 12227-010 Såo José dos Campos, SP-Brazil \\ Tel: +55-12-3456475, Fax: +55-12-3456468 \\ [sidnei,correia,corina]@dpi.inpe.br \\ Alejandro César Frery \\ UFPE - DI \\ CP 7851 \\ 50732-970 Recife, PE, Brazil \\ Tel: +55-81-2718430, Fax: +55-81-2718438 \\ frery@di.ufpe.br
}

In this paper a SIR-C data is used to assess the discriminatory capability of full polarimetric data for several classes of landuse. It is analysed the contribution of each type of data (phase difference, intensity ratio, intensity pair and intensity-phase difference pair), using the Iterated Conditional Modes (ICM) classifier. It is shown that each class was better classified using a different type of polarimetric data. The result of the classification (measured by the confusion matrix and the Kappa coefficient of agreement) was considered very good, allowing the discrimination of nine land use classes, which includes different cultivation stages of some crops.

\section{INTRODUCTION}

Digital classification is one of the most extensively used tools in Remote Sensing applications. Several classical statistical classifiers are based on the assumption that the data are Gaussianly distributed. However, when radar data are used, this assumption is seldom verified, especially in the case of polarimetric radar images. Therefore, the development of new techniques and methods to classify digital radar images has been the focus of attention in several studies [2], [8], [10].

Usually, these new techniques and methods model the radar data by the multiplicative model [6]. Statistical models for multi-look polarimetric data are derived from the covariance matrix, which exhibit a complex Wishart distribution [4], [7].

In [9] it was developed the distributions of the univariate (phase difference and intensity ratio) and bivariate (intensity pair and intensity-phase difference pair) multi-look polarimetric data by assuming a constant backscatter. In this paper these distributions are used to classify a radar polarimetric data using the ICM classifier.
The objective of this paper is to quantitatively analyse the contribution of each type of data (phase difference, intensity ratio, intensity pair and intensity-phase difference pair) for the discrimination of several classes.

\section{ICM CLASSIFIER}

The ICM classifier incorporates the multiplicative and a contextual model for the observations (returned radar data) and classes, respectively. The Markovian model known as Potts-Straus is assumed to describe the classes. The ICM algorithm consists of the iterative improvements on a classification, using the information of a given observation and the classes of its neighboring. This improvement is obtained by maximizing the a posteriori distribution of the classes, which is given by:

$$
L\left(\xi^{\prime}\right)=f_{\xi^{\prime}}\left(z_{s}\right) \exp \left(\beta \#\left\{t \in \partial_{s}: \xi_{t}=\xi^{\prime}\right\}\right),
$$

where $f_{\xi^{\prime}}\left(z_{s}\right)$ is the density associated to class $\xi$, which has radiometric value $z_{s}$ on co-ordinate $s, \beta$ is a real parameter that quantifies the influence of the neighbouring classes and it is estimated iteratively and $\partial_{s}$ is the set of neighbouring coordinates around $s$. This expression can be reduced to the Maximum Likelihood (ML) classifier and to Mode Filter, when $\beta=0$ and $\beta \rightarrow \infty$, respectively. For more details of the algorithm, the reader is referred to [1], [5] and [10].

\section{DATA AND METHODOLOGY}

The images selected for this work are those from the SIRC/X-SAR mission acquired over Bebedouro region, Pernambuco State, Brazil, using full polarimetric L and C bands. This area corresponds to an irrigated region with

\footnotetext{
'This work was supported by grants from PPG-7/FINEP (0808/95 and 0816/95, 6.6.96.0473.00 and 6.6.96.0474.00), CNPq (Proc. 300927/92-4 and 523469/96-9) and FACEPE (APQ 0707-1.03/97).
} 
several types of crops. The central co-ordinates of the study area is $09^{\circ} 07^{\prime} \mathrm{S}, 40^{\circ} 18^{\prime} \mathrm{W}$. The main parameters of these images are presented in Table 1 .

Table 1: SIR-CIX-SAR Image main parameters.

\begin{tabular}{|l|l|}
\hline Acquisition date & April 14, 1994 \\
\hline Size of the images & $407 \times 370$ pixels \\
\hline Frequency & $\mathrm{L}(1.254 \mathrm{GHz})$ and $\mathrm{C}(5.304 \mathrm{GHz})$ \\
\hline Polarisation & $\mathrm{HH}, \mathrm{HV}, \mathrm{VV}$ and $\mathrm{VH}$ \\
\hline Incidence angle & $49.496^{\circ}$ \\
\hline Nominal number of looks & 4.7854018 \\
\hline Pixel spacing & $12.5 \mathrm{~m}$ in range and azimuth \\
\hline
\end{tabular}

Fig. Ia and $\mathrm{Ib}$ present the colour compositions for $\mathrm{L}$ and $\mathrm{C}$ bands, respectively, of the data set under study. These figures also present the training and test samples.

The classes of interest are presented in Table 2, where their respective colour keys (the colours with which they will be represented in the classification) and sizes of training and test samples. There are two stages of corn (Cornl up to 124 days, and Corn 2 with 133 days of cultivation), and three stages of soybean (Soybean 1 with 52 days, Soybean 2 with 66 days and Soybean 3 between 76 and 113 days of cultivation).

Table 2: Classes of interest, colour keys, training and test samples.

\begin{tabular}{|c|c|c|c|}
\hline Classes & Colour & $\begin{array}{c}\text { \#Training } \\
\text { Pixels }\end{array}$ & $\begin{array}{c}\text { \#Test } \\
\text { Pixels }\end{array}$ \\
\hline River & Blue & 4949 & 3844 \\
\hline Caatinga & Green & 5177 & 3585 \\
\hline Prepared Soil & Red & 3221 & 2101 \\
\hline Soybean1 & Gray & 961 & 436 \\
\hline Soybean2 & Magenta & 914 & 550 \\
\hline Soybean3 & Brown & 1849 & 1086 \\
\hline Tillage & Cyan & 934 & 530 \\
\hline Com1 & Yellow & 3039 & 1645 \\
Com2 & Purple & 847 & 378 \\
\hline
\end{tabular}

In [2] a detailed analysis of many ML/ICM classifications for each band ( $\mathrm{L}$ and $\mathrm{C}$ ) were performed, using phase difference, intensity ratio, intensity pair and intensity-phase difference pair data set and their corresponding distributions [9]. All combinations of polarisation for each band were analysed. Söme of the results area also presented in [3]. It was noted that the information that these data set carry is very specific, and each class was better classified with a different data. By the analysis of all ICM classification and their corresponding confusion matrix it was found the polarimetric data that best discriminate each class. The result of this analysis is shown in Table 3.

Based on the results of the ICM classifications using the data presented in Table 3 , a set of Boolean operations were performed in order to form a final classification. After this operations, several pixels were unclassified. To solve this problem, each unclassified pixel was assigned to the class with a higher number of pixels (mode) within a window of $5 \times 5$ pixels, considering all the data presented in Table 3.

The final classification is shown in Fig 1c. The confusion matrix is presented in Table 4, where the number inside the parenthesis represents the percentage of classified pixels. This matrix has an associated Kappa coefficient of agreement of 0.8235 , with variance of $1.2124 \times 10^{-5}$.

Table 3: Data which best discriminate each class.

\begin{tabular}{|c|c|}
\hline Classes & Data \\
\hline River & Intensity Pair C-HVVV \\
\hline Caatinga & Intensity Pair L-HVVV \\
\hline Prepared Soil & $\begin{array}{c}\text { Intensity Pair C-HVVV and Phase } \\
\text { Difference C-HHVV }\end{array}$ \\
\hline Soybean1 & Intensity-Phase Difference Pair L-HHVV \\
\hline Soybean2 & $\begin{array}{c}\text { Intensity Pair C-HHVV and Intensity Pair } \\
\text { L-HVVV }\end{array}$ \\
\hline Soybean3 & Intensity Pair L-HHVV \\
\hline Tillage & Intensity-Phase Difference Pair L-HHVV \\
\hline Corn1 & $\begin{array}{c}\text { Intensity Pair L-HVVV and Intensity- } \\
\text { Phase Difference Pair L-VVHH } \\
\text { Intensity Pair L-HHVV }\end{array}$ \\
\hline
\end{tabular}

Comparing with the individual classifications, the use of this methodology allowed, in general, to decrease the misclassification among classes, in spite of the decrease of the number of pixels correctly classified. The three classes of Soybean presented the smallest overall accuracy (around to $56 \%$ ), while the overall accuracy for the others classes were more than $71 \%$. The greatest confusion was observed between Corn 2 and Soybean2, which was close to $26 \%$.

Although the Soybean 3 class has had high overall accuracy $(84 \%)$ with intensity ratio L-HHVV classification, this data was not selected to contribute for the final classification, because it has a high degree of confusion among classes.

\section{CONCLUSIONS}

The analysis of SIR-C images showed that each class was better classified using different type of data (phase difference, intensity ratio, intensity and intensity-phase difference pairs), highlighting the importance of having the full polarimetric data for land use classification. The classification methodology, which uses all these information, showed to be very efficient for the intent purpose. It was possible the discrimination of different stages of Corn and Soybean.

In general, the $\mathrm{L}$ band seems to carry more information than $C$ band to discriminate the study classes, but the $C$ band was useful to improve the classification of River, Prepared Soil and middle stage of Soybean.

The ICM classifier showed to be a good method for classifying the polarimetric radar data.

The obtained results were very encouraging for continuing the study of the potentiality of polarimetric data for land use classification. 


\section{REFERENCES}

[1] J. Besag Toward Bayesian image analysis. J. App. Stat., 16(3):395-407, 1989.

[2] A.H. Correia Desenvolvimento de classificadores de máxima verossimilhança e ICM para imagens SAR polarimétricas. (MSc in Remote Sensing) - Instituto Nacional de Pesquisas Espaciais. São José dos Campos, SP, Brazil, Dez., 1998.

[3] A.H. Correia; C.C. Freitas; A.C. Frery and S.J.S. Sant'Anna. A user-friendly statistical system for polarimetric SAR image classification. Revista de la Asociación Española de Teledetección. In press.

[4] Du, L.J.; Lee, J.S. Polarimetric SAR image classification based on target decomposition theorem and complex Wishart distribution. In: IGARSS'96 International Geoscience and Remote Sensing Symposium'96, Lincoln, May. 27-31, 1996. Remote Sensing for a Sustainable Future. IEEE, 1996. v. I, p. 439-441.

[5] A.C. Frery Algumas ferramentas estatisticas na sintese, processamento e análise de imagens de radar de abertura sintética. São José dos Campos, $\mathrm{PhD}$ thesis in Applied Computing . Instituto Nacional de Pesquisas Espaciais, 1993.

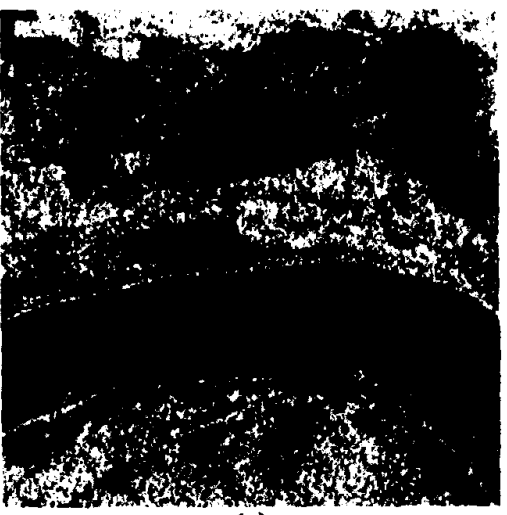

(a)

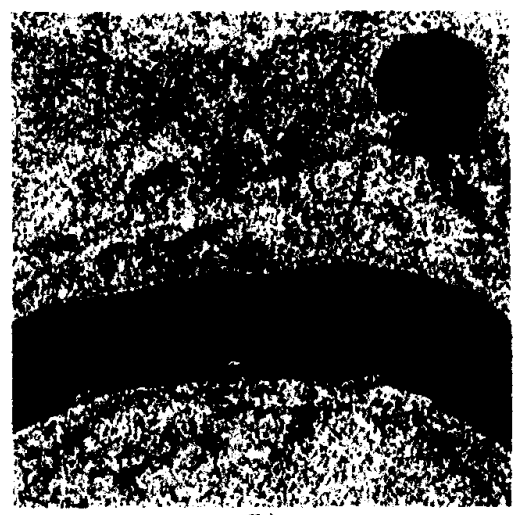

(b)
[6] A.C. Frery, H.J. Muller, C.C.F. Yanasse and S.J.S. Sant Anna A model for extremely heterogeneous clutter. IEEE Transactions on Geoscience and Remote Sensing, 35(3):648-659, 1997.

[7] J.S. Lee and M.R. Grunes Feature classification using multi-look polarimetric SAR imagery. In: IGARSS'92 International Geoscience and Remote Sensing Symposium'92, Houston, May 26-29, 1992. International Space Year: Space Remote Sensing. Piscataway, IEEE, 1992. v. I, p. 77-79.

[8] J.S. Lee and M.R. Grunes Classification of multilook polarimetric SAR imagery based on complex Wishart distribution. Int. J. Rem. Sens., 15(11):2299-2311, 1994.

[9] J.S. Lee, K.W. Hoppel and S.A. Mango, Intensity and phase statistics of multi-look polarimetric and interferometric SAR imagery. IEEE Trans. Geosc. Rem. Sens,. 32(5):1017-1028, 1994.

[10]P.R. Vieira Desenvolvimento de classificadores de maxima verossimilhança e ICM para imagens SAR. (MSc in Remote Sensing) - Instituto de Nacional de Pesquisas Espaciais. Såo José dos Campos, SP, Brazil, 1996. 251 p. (INPE-6124-TDV/585).

Fig. 1: Colour compositions of the original data R-HH, G-HV, B-VV, L band with training sets (a), C band with test sets (b) and final classification (c).

Table 4: Confusion matrix of the classification.

\begin{tabular}{|c|c|c|c|c|c|c|c|c|c|c|}
\hline & River & Cantinga & Prepar. Soil & Soybean-1 & Soybean-2 & Soybean-3 & Tillage & Cora-1 & Corn-2 \\
\hline River & $3844(100)$ & 0 & 0 & 0 & 0 & 0 & 0 & 0 & 0 \\
\hline Cantigga & 0 & $3160(88.2)$ & 0 & 0 & $24(0.7)$ & $209(5.8)$ & 0 & $110(3.1)$ & $79(2.2)$ \\
\hline Prepar. Soil & 0 & 0 & $1682(80.1)$ & $6(0.3)$ & $1(0.1)$ & 0 & $412(19.6)$ & 0 & 0 \\
\hline Soybean-1 & 0 & $1(0.2)$ & $12(2.8)$ & $252(57.8)$ & $22(5.5)$ & 0 & $75(17.2)$ & $1(0.2)$ & $73(16.7)$ \\
\hline Soybean-2 & 0 & $10(1.8)$ & $3(0.5)$ & $59(10.7)$ & $299(54.4)$ & $16(2.9)$ & $10(1.8)$ & 0 & $153(27.8)$ \\
\hline Soybean-3 & 0 & $187(17.2)$ & 0 & $22(2.0)$ & $206(19.0)$ & $618(56.9)$ & $39(3.6)$ & $1(0.1)$ & $13(1.2)$ \\
\hline Tillage & 0 & 0 & 0 & $9(1.7)$ & $2(0.4)$ & $21(4.0)$ & $473(89.2)$ & 0 & $25(4.7)$ \\
\hline Cora-1 & 0 & $28(1.7)$ & $33(2.0)$ & 0 & $20(1.2)$ & $14(0.9)$ & $2(0.1)$ & $1501(91.3)$ & $47(2.9)$ \\
\hline Corn-2 & 0 & 0 & 0 & 0 & $90(23.8)$ & $15(4.0)$ & $5(1.3)$ & 0 & $268(70.9)$ \\
\hline
\end{tabular}

